\title{
Mutaciones estatales y el complejo hidrocarburífero de formosa*
}

\author{
Recibido: 20 de febrero de 2020 - Aprobado: 3 de marzo de 2020 \\ https://doi.org/10.22395//seec.v22n53a9
}

\author{
Giuliano Ernesto Fabián**
}

\section{RESUMEN}

El presente trabajo analiza el proceso de mutación del Estado y la dinámica de políticas públicas productivistas fragmentarias que se van acoplando a las alteraciones, continuidades y reforzamientos acaecidos en el complejo hidrocarburífero de Formosa, Argentina en el marco de su inserción periférica intra-nacional y supranacional entre 1991-2012. Con una metodología que combina fuentes documentales con datos cuantitativos, se observa al Estado provincial mutando nuevas funciones económicas cuyo entramado resulta similar a lo que Jessop llama Estado workfarista. De este proceso se estudia cómo la dinámica de plegamiento de políticas públicas productivistas fragmentarias configuran un patrón regulativo escalar neoliberal en el complejo hidrocarburífero, lo que facilita la penetración del gran capital, el control y el manejo de activos como el petróleo y su explotación extractivista-exportadora. Esa lógica de acumulación hace emerger relaciones asimétricas de poder en lo político, económico y social. De modo que, el espacio económico-territorial en estudio se transforma con la continuidad de desigualdades persistentes.

\section{PALABRAS CLAVE}

Estado; neoliberalismo; complejo hidrocarburífero; extractivismo.

\section{CLASIFICACIÓN JEL}

$\mathrm{O} 1, \mathrm{O} 13, \mathrm{O} 38, \mathrm{Q} 32, \mathrm{R} 1$

\section{CONTENIDO}

Introducción; 1. Mutación del capitalismo, cambios en la estatalidad y el caso formoseño; 2. El complejo hidrocarburífero formoseño y el Estado workfarista; Conclusiones; Bibliografía.

- El presente artículo de investigación expresa una parte del objeto de estudio de la tesis de Doctorado del autor en el Programa de Doctorado en Ciencias Sociales de la Universidad de Buenos Aires (UBA), Buenos Aires, Argentina.

* Economista, Universidad Nacional de Córdoba, Córdoba, Argentina. Magíster en Gestión Territorial y Desarrollo, Universidad Nacional de Rosario, Santa Fe, Argentina. Doctor en Ciencias Sociales, Universidad de Buenos Aries, Buenos Aires, Argentina. Docente e investigador de la Facultad de Administración, Economía y Negocios (FAEN), Universidad Nacional de Formosa (UnaF), Formosa, Argentina. Correo electrónico: giulianoernesto02@gmail.com. Orcid: https://orcid.org/0000-00029699-8148 


\title{
State Mutations and the Formosa Hydrocarbon Complex
}

\begin{abstract}
The present work analyzes the mutation process of the State and the dynamics of fragmented productivist public policies, which are coupled with alterations, continuities and reinforcements in the hydrocarbon complex of Formosa, Argentina, in the framework of its intra-national and supranational peripheral insertion between 1991-2012. Following a methodology that combines documentary sources with quantitative data, the provincial State, mutating new economic functions with frameworks that are similar to what Jessop calls the Workfare State. In this process, how dynamics of the folding of fragmentary productivist public policies configure a neoliberal scalar regulatory pattern in the hydrocarbon complex, which facilitates the penetration of big capital, control and management of assets such as oil and its extractive-export exploitation are studied. This logic of accumulation leads to the emergence of asymmetrical power relations in the political, economic and social spheres. Thus, the economic-territorial space under study is transformed with the continuity of persistent inequalities.
\end{abstract}

\section{KEYWORDS}

State; neoliberalism; hydrocarbon complex; extractivism.

\section{JEL CLASSIFICATION}

O1, O13, O38, O32, R11

\section{CONTENT}

Introducction; 1. Mutation of capitalism, changes in statehood and the case of Formosa; 2. The Formosan hydrocarbon complex and the Workfare State; Conclusions; Bibliography.

\section{Mutações estatais e o complexo de hidrocarboneto de Formosa, Argentina}

\section{RESUMO}

Este trabalho analisa o processo de mutação do Estado e a dinâmica de políticas públicas produtivistas fragmentadas que vão se vinculando às alterações, continuidades e reforços ocorridos no complexo de hidrocarboneto de Formosa, Argentina, no âmbito de sua inserção periférica intranacional e supranacional entre 1991 e 2012. Com uma metodologia que combina fontes documentais com dados quantitativos, observa-se o Estado provincial transformando novas funções econômicas cuja estrutura resulta similar ao que Jessop denomina "Estado workfarista". Desse processo, estuda-se como a dinâmica de retrocesso de políticas públicas produtivistas fragmentadas configuram um padrão regulatório escalar neoliberal no complexo de hidrocarboneto, o que facilita a penetração do grande capital, do controle e gestão dos ativos como o petróleo e sua exploração extrativista-exportadora. Essa lógica de acumulação faz surgir relações assimétricas de poder no político, econômico e social. Portanto, o espaço econômico-territorial em estudo se transforma com a continuidade de desigualdades persistentes.

\section{PALAVRAS-CHAVE}

Estado; neoliberalismo; hidrocarboneto; extrativismo

\section{CLASSIFICAÇÃO JEL} $\mathrm{O} 1, \mathrm{O} 13, \mathrm{O} 38, \mathrm{Q} 32, \mathrm{R} 1$

\section{CONTEÚDO}

Introdução; 1. Mutação do capitalismo, mudanças na estatalidade e no caso de Formosa; 2. O complexo de hidrocarboneto de Formosa e o Estado workfarista; Conclusões; Bibliografia. 


\section{INTRODUCCIÓN}

Formosa es una de las jurisdicciones subnacionales, que, en términos de Vaca y Cao (2004, p. 73-75), integran la periferia' rezagada de Argentina. Esta se distingue -para estos autores- por su bajo desarrollo relativo, sus indicadores de deterioro social y una aguda dependencia del sector público. En ella se observan además corrientes migratorias hacia las áreas centrales y deterioro en la participación relativa en el PBI. Destaca Giuliano (2015, p. 281-291) que la economía de Formosa se caracteriza por producir bienes provenientes de las actividades intensivas en recursos naturales, marcada por la polaridad latifundio-minifundio, el extractivismo y por transitar un acentuado proceso de fragmentación y tercerización de la estructura de empleo. Schorr, Ferreira y Gorenstein (2012, p. 55) señalan una escasa industrialización y dependencia con las principales regiones centrales del país, su vinculación subordinada dentro de la matriz productiva nacional está trazada a partir de grandes empresas nacionales y extranjeras.

Las acciones de la élite estatal que comanda el Estado provincial han trazado -según Brenner, Peck y Theodore (2011, p. 21) su propio sendero del proceso de neoliberalización² a través de la profundización y redefinición de este rasgo central de la formación social provinciana. El trabajo propone acercase a uno de los aspectos de estas acciones que permiten observar cómo la dinámica de plegamiento de las políticas públicas productivistas fragmentarias configuran un patrón regulativo escalar neoliberal en el complejo hidrocarburífero y facilitan la penetración del gran capital, el control y explotación extractivista-exportadora del petróleo, pero luego se combina -en complemento- con las ideas que Fernández, Amin y Vigil (2008, p. 12) denominan la nueva ortodoxia regionalista (NOR), como estrategia de promoción al desarrollo, aunque sus acciones le dan continuidad y reelaboración al proceso neoliberal.

1 Se rescata aquí el concepto centro-periferia, no en el sentido clásico del debate en las ciencias sociales, sino en el contexto en el que el mundo se debate entre multilateralidad y multipolaridad. Para Norodowsky y Merino (2015), la multilateralidad se da en los países emergentes. Son mercados del capitalismo transnacionalizado, múltiples lados de un mismo polo de poder y de un mismo proyecto político estratégico global. La multipolaridad, en cambio, se da a partir de la emergencia de bloques de poder (o Estados continentales) con proyectos políticos estratégicos propios, que desafían el orden vigente y buscan convertirse en polos de poder con capacidad de configuar el orden mundial. Arrighi y Silver (2001) señalan la diversidad de periferias o como lo denominan, sur en un mundo multipolar. En esa diversidad, es placible encontrar sur o periferias muy diferentes, como África, o las que emergen, como Asia Oriental o China, en particular. Formosa se ubica entonces en el espacio del sur, siendo uno de esos sures o periferia particular caracterizada como rezagada.

2 Al respecto, el trabajo de Brenner, Peck y Theodore (2011) introduce el marco teórico para pensar al neoliberalismo como un proceso abigarrado, geográficamente desigual y dependiente de una trayectoria previa (path-dependent) que se ha diseminado en toda la economía mundial desde la década de los ochenta. 
Para su seguimiento, en la primera parte se hace un breve recorrido conceptual por la mutación del capitalismo, los cambios en los ámbitos funcional y espacial del Estado y en esa dinámica, la emergencia del patrón regulativo aludido. En la segunda parte se intenta dar cuenta del proceso de acoplamiento de dicho patrón a las lógicas de intereses que penetran y explotan el petróleo, pari passu, consolidan un perfil productivo extractivista-exportador en tanto la población local -mayoritariamente indígena y criolla- es dirigida por la acción conjunta de los actores hidrocarburíferos dominantes, religiosos y el Estado al ideario de la NOR, como promesa para alcanzar el desarrollo local en espacios rurales en los que la degradación ambiental y las desigualdades sociales persisten. Finalmente, las conclusiones procuran articular los resultados observados, en función del marco conceptual y el objetivo propuesto.

\section{MUTACIÓN DEL CAPITALISMO, CAMBIOS EN LA ESTATALIDAD Y EL CASO FORMOSEÑO}

La emergencia del paradigma o como lo llama Lipietz (1994, p. 18), el modelo de desarrollo posfordista, modificó la organización territorial de las formas de acumulación y del modo de regulación. Su dinamización relativizó el ámbito nacional y jerarquizó el global-local o regional como eje de los procesos de producción y acumulación del capital. Para ello, adoptó patrones más dinámicos y flexibles en ambientes de proximidad ${ }^{3}$ en redes e históricamente heterogéneos, de la mano de un núcleo de fundamentos teóricos luego institucionalizados -como se observa más adelante-, que transitaron desde los distritos industriales ${ }^{4}$ hasta el enfoque evolucionista-institucionalista ${ }^{5}$ con los milieux innovateurs ${ }^{6}$, su evolución a los sistemas regionales de innovación con Cooke y Morgan (1999) y la configuración de clúster propuesta por Porter (1998). Todas ellas comulgan en sostener el ascenso de los espacios gobal-local o regionales como núcleos estratégicos y desencadenantes de procesos de industrialización y desarrollo.

3 Amin (1998, p.77) explica que en la visión institucionalista la proximidad comprende los parámetros sociales e institucionales para la acción económica, tales como: el poder de las lógicas y tradiciones de comportamientos locales; las propiedades de las redes de contacto cara a cara; la calidad de las instituciones locales, las normas sociales y las convenciones.

4 La definición original de distrito industrial se debe a Alfred Marshall en 1920, la rescató y actualizó Becattini (1992, p. 40) quien lo definió como: "entidad socioterritorial caracterizada por la presencia activa tanto de una comunidad de personas como de una población de empresas en un espacio geográfico e históricamente dado".

5 Ambos cuerpos de pensamiento, expresó Amín (1998, p.71), destacan la idea de que la vida económica es un proceso instituido y una actividad socialmente enraizada y por lo tanto, su evolución está sujeta a un contexto específico y una trayectoria histórica.

6 Benko y Lipietz $(1994$, p.7) señalan que los medios innovadores o milieux innovateurs los desarrollan de forma pionera por el equipo europeo franco-italiano Gremi (Grupo de Investigación Europeo sobre los Medios Innovadores, Asociación Phillippe Aydalot). 
En ese contexto, durante el súmmum del neoliberalismo en la década de 1990, aunque ya se venía desarrollando desde mediados de la década de 1970, el país profundizó el proceso de ajustes y reformas estructurales impulsados por el Consenso de Washington (CW). En esa línea de ideas, en 1992 se configuró en Argentina un patrón regulativo escalar de regulación a favor de los capitales extranjeros y nacionales que habilitó la privatización de la empresa estatal Yacimiento Petrolíferos Fiscales (YPF), la provincialización y el dominio de estas jurisdicciones sobre los recursos hidrocarburíferos. Dicho patrón se estructuró con la Ley Nacional 24.1457, y se selló con la reforma constitucional de $1994^{8}$.

Esto es, se modificaron: el modelo de centralidad estatal ${ }^{9}$ y las estrategias de desarrollo, lo cual implicó -argumentan Fernández y García Puente (2010, p. 144)-en esta década la desaparición total de la industrialización basada en la sustitución de importaciones. De este modo, se desplazó el Estado nacional en la dinámica de acumulación nacional, que en hechos se tradujo -como señalan Rofman y Romero (1997, p. 253) en el paso de un Estado de bienestar a un Estado subsidiario.

Con el crecimiento de las reformas neoliberales -como se adelantó al inicio de esta primera parte- se comenzó a desarrollar un conjunto de contribuciones académicas preveniente de los países centrales. Estas contribuciones se agruparon dentro de lo que Fernández, Amin y Vigil, (2008, p. 12) denominan NOR. Hacia mediados de la década de 1990, esta perspectiva penetró en los países periféricos y se propagó de manera acrítica la lectura neoliberal del desarrollo capitalista, se institucionalizó de la mano de intelectuales e instituciones destacadas del mundo académico y supranacional a nivel regional, fues así como la NOR se constituyó en una plataforma común.

Durante el transcurso de este período - caracterizado por profundos cambiosFormosa estuvo signado por tres rasgos institucionales fundamentales: 1) las modificaciones sucesivas (en dos oportunidades) de la Carta Magna de la provincia; 2) la continuidad hegemónica del partido-Estado en la dirección política y administrativa del Estado; y 3) a partir de los dos primeros, la implementación dominante del modelo formoseño para el desarrollo provincial (MFDP).

7 En los inicios de la década de 1990 ya se habían sancionado los tres decretos desregulatorios de la actividad (1.055, 1.212 y 1.589, basados en la reforma parcial a la Ley 17.319 que introdujo la Ley 23.696). Poco después se sancionó la Ley 24.145 de privatización de YPF y provincialización de los recursos hidrocarburíferos.

8 El artículo 124 -en la parte final- de la Constitución Nacional reformada en 1994 incorporó el reconocimiento del dominio originario de las provincias sobre sus riquezas del subsuelo.

9 También denominado matriz estadocéntrica, en el cual el Estado se constituyó como actor político, árbitro y al mismo tiempo, arena de disputas debido a la distribución del ingreso y los conflictos sociales (Cavarozzi, citado por Fernández y García Puente, 2010). 
Esos rasgos se comenzaron a vislumbrar cuando los marcos legales e institucionales de Formosa se transformaron en 1991 con la primera reforma constitucional durante la gestión del gobernador Vicente Bienvenido Joga -la cual abrió las puertas a su reelección (Art. 129 de la Constitución Provincial de 1991) y este repitió la fórmula para el cargo de vicegobernador con Gildo Insfrán. Dicha reforma constitucional consagra nuevos institutos y derechos civiles ${ }^{10}$, adelantándose a los que se incluyeron en la Constitución Nacional, reformada en 1994.

Pero a su vez, es el comienzo de un poder hegemónico que tendrá su continuidad con la elección de Gildo Insfrán (1995-1999) y la cristalización del ideario redactado en el preámbulo de la Constitución de 1991, publicado en la Honorable Cámara de Diputados de la Provincia de Formosa (1991, p.1): "I... plasmar el modelo formoseño para un proyecto provincial [...]". En la cual el grupo dominante que encarnaró política y económicamente ese proceso, al que denominamos partido-Estado", se constituyó desde entonces, en un factor determinante, para el asentamiento de espacios de acumulación, vinculados a la explotación de los recursos naturales.

Pese a que la Constitución Provincial solo permitía una reelección (artículo $129^{12}$ de la Constitución Provincial de 1991), el Superior Tribunal de Justicia hizo una interpretación de dicho artículo con la decisión de habilitar a Gildo Insfrán para que participara en las elecciones de dicho año, lo cual lo consagró gobernador nuevamente para el período 1999-2003.

En el año, el Poder Ejecutivo Provincial (PEP) avanzó sobre el Poder Judicial, aumentó el número de miembros de la Corte local de tres a cinco (Sued, 2006). Hacia

10 Sin pretender hacer un examen exhaustivo del texto constitucional, se mencionan, a manera de ejemplo, los institutos que se incorporaron al texto constitucional: la Fiscalía de Asuntos Administrativos, el Consejo Económico y Social y el Defensor del Pueblo. Asimismo, se incorporaron los derechos de pueblos originarios, se protegió el medio ambiente y recursos naturales, se consagraron derechos a los consumidores y usuarios, amas de casa, amparo a las madres solteras desprotegidas, entre otros.

11 La construcción de la hegemonía partido-Estado la lidera la elite dirigente del partido justicialista local, en la que partido gobernante y Estado se mezclan, fusionan y conjugan con la impronta de conducciones personalistas desde el Poder Ejecutivo Provincial (PEP), apoyada por dicha elite, en articulación con grupos empresariales, vinculados a la ganadería, construcción, empresariado forestal, comercial, gremial, partidos políticos y organizaciones sociales a los cuales abre la posibilidad de ocupar espacios de poder a nivel Legislativo o Ejecutivo. Política y electoralmente, se forja a través de una herramienta clave: la Ley Provincial $N^{\circ}$ 657, sancionada el 1 de abril de 1987 (que irá incorporando algunas modificaciones), conocida como Ley de Lemas.

12 El artículo 129 habilitaba al gobernador Vicente Joga en 1991 a una reelección de su mandato, nuevamente con la fórmula con vicegobernador Gildo Insfrán. Ello le permitió a este último sucederlo por un nuevo período (1995-1999) como gobernador, ya que Insfrán ya había sido reelecto sucediendo al anterior gobernador. Para 1999, según el artículo en cuestión, no estaba habilitado para presentarse a una nueva elección para ninguno de ambos cargos, sin el intervalo de un período. Esta limitación fue sometida a la interpretación del Superior Tribunal de Justicia que, con dos votos a uno negativo, convalidó la decisión en un ambiente de gran presión política sobre los integrantes del Poder Judicial de la provincia. 
finales del 2002 se hizo evidente que el gobernador buscaba una nueva reelección en un ambiente social y económico convulsionado, dramático y teñido por las emergencias económicas, a raíz de la situación de crisis del país y a nivel provincial.

A su vez, ese escenario resultó ser crucial para la construcción de una arquitectura de leyes y arreglos escalares verticalizantes que facultaran con amplios poderes al PEP para decidir sobre el patrimonio del Estado ${ }^{13}$. Junto a este plexo normativo, se prorrogaron las Leyes de Emergencia Económica 1.296 y 1.342 que se habían puesto en vigencia desde 1991 y que tendrían una continuidad sistemática a través de la sanción de las leyes nacionales y provinciales que la prorrogaron durante todo el período analítico propuesto ${ }^{14}$.

En ese escenario, la amplia mayoría de diputados oficialistas de la legislatura que seguía la marcha incesante del PEP en su acumulación de atribuciones terminó facilitando la declaración de necesidad de la reforma constitucional, abrió los comicios a tal efecto el $1^{\circ}$ de junio de 2003.

Un elemento clave que no se puede soslayar en este proceso es la aparición en este escenario político provincial del presidente Néstor Kirchner, había asumido como primer mandatario de la nación el 25 de mayo del 2003. El 28 de ese mes, a solo cuatro días de los comicios para la elección a Convencionales Constituyentes, el presidente arribó a Formosa y manifestó su apoyo al proceso político que se encontraba en desarrollo y al gobernador Insfrán, con la firma junto al PEP del Acta de Reparación Histórica (ARH) ${ }^{15}$.

13 Se trata de la Ley 1.367 que adhiere a la Ley Nacional de emergencia económica 25.561. Con ello, se le otorga al PEP poderes extraordinarios (art. 10) que le facultan a realizar todas las acciones, trámites, convenios, suscribir documentación, etc,. que resulten necesarios, pudiendo -entre otras-modificar plazos, intereses, modalidades de pago, montos, etc., de las operaciones originales. Estas comprendían los títulos públicos, bonos, letras de tesorería, préstamos, contratos de fideicomiso, etc., así como su negociación, canje, operaciones de pase, afectación en garantía, y/u otras modalidades de operaciones financieras conforme a los usos y condiciones de mercado, del modo que resultara más favorable para el fisco y la economía provincial. Se le facultó a refinanciar y reprogramar las acreencias de cualquier naturaleza del estado provincial que se mantuvieran con distintos organismos oficiales y/o entidades autárquicas, centralizadas, descentralizadas, y/o persona física o jurídica.

14 Así por ejemplo, a través de la Ley provincial 1.576 adhirió la provincia de Formosa a la Ley Nacional 26.729 que prorroga la vigencia de su similar (26.204), prorrogada a su vez por las leyes. 26.339, 26.456 y 26.563, hasta el 31 de diciembre de 2013, que son las prórrogas de la Ley 25.561. Simultáneamente, a nivel meso-regional, se prorrogaron la vigencia de las Leyes provinciales 1296, 1342, 1472, 1367, $1485,1503,1518,1530$ y 1544, así como todas las normas reglamentarias y aclaratorias dictadas en su consecuencia, manteniéndose el "estado de emergencia pública" durante el término establecido en la mencionada Ley Nacional.

15 El ARH implicó para Formosa, la percepción de un volumen de flujo de fondos provenientes del Estado nacional con destino a múltiples infraestructuras, que se detallan en el PET Formosa 2015, que se ejecutaron desde 2005 . 
De esta manera, tras ganar las elecciones el Partido Justicialista con el 56 \%, se instituyó el ambiente de la reforma constitucional, con amplia mayoría de dicho partido político. La reforma impuso la reelección ilimitada para todos los cargos electivos $^{16}$, lo que le permitiría a Gildo Insfrán a acceder a su tercer (2003-2007) y luego a un cuarto mandato (2007-2011), y continuar de manera ininterrumpida en el período (2011-2015) a la actualidad. Desde la reforma de 1991 hasta la de 2003, se centralizó el poder en el PEP17, se debilitaron el Poder Judicial y el Poder Legislativo ${ }^{18}$ con pérdida de protagonismo de este último (Legislatura de Formosa, 2003).

Podremos observar entonces -en un escenario de arreglos escalares verticalizantes y hegemónicos- que la puesta en funcionamiento de la plataforma común, como indican Peck y Tickell (1994, p. 285), origina un doble vínculo entre las escalas ${ }^{19}$ territoriales local/global en tanto espacios estratégicos del desarrollo:

[...] los ámbitos locales se encuentran determinados por las dinámicas globales y lo local es resignificado como configurador de los procesos globales. Sin embargo, esas relaciones son asimétricas e inestables -y más aún en territorios periféricos-, porque las estrategias locales, al favorecer la libertad de acción del capital, se inclinan a la voluntad de la competencia global.

Asimismo, entre las regiones se alientan relaciones competitivas que consolidan y acentúan los procesos fragmentarios de reproducción socioespacial y, de este modo, provocan nuevos desequilibrios y desigualdades.

Hacia finales del 2001 llegó a su clímax la crisis del proceso neoliberal. Esto implicó la salida abrupta de la convertibilidad ${ }^{20}$ y más en general, un giro hacia

16 Comprende a los de los poderes legislativo, ejecutivo, así como a los municipios. Art. 105; 132 y 179 de la Constitución Provincial de 2003.

17 Véase los artículos 62 y 65 de la Constitución Provincial.

18 Véase el artículo 120, incisos 4 y 5, y el artículo 170, inciso 6 de la Constitución Provincial.

19 Las escalas como el Estado nación, provincia, ciudad o cualquier otra, como dice Smith (citado por González, 2005, p. 11), son "expresiones mismas de la organización de los procesos sociales". Desde una observación más precisa, se entiende como "representaciones" impulsadas por los actores académicos, institucionales y económicos que despliegan estrategias destinadas a resolver su reproducción y los conflictos de poder a los que esas estrategias dan lugar. Ello conlleva el posicionamiento de una determinada organización espacial de las dinámicas económicas, sociales e institucionales y a partir de ello, una configuración dada de las escalas -globales, nacionales y locales- y sus vínculos, en concordancia con esas estrategias (Fernández, Vigil y Seval, 2012, p. 28).

20 La salida se materializa con la Ley 25.561 que modifica con notoriedad el tipo de cambio real (por lo menos hasta el 2008), con ello, los precios relativos y el consecuente cambio en el eje de la acumulación, viró principalmente hacia los sectores productores de bienes transables (Azpiazu, Manzanelli y Schorr, 2011, p. 98). 
una revalorización de la autonomía relativa del Estado para orientar el desarrollo económico capitalista. En tal sentido, por lo menos algunas de las características más ostensibles de las políticas macroeconómicas del paquete de medidas del neoliberalismo se dejaron de lado, como señala Jessop (2010, p. 70) en su época de plenitud en la década de 1990.

No obstante, ello no implicó que el neoliberalismo haya perdido su esencia y dado lugar a otro régimen de regulación distinto. La interpretación de un supuesto fin del neoliberalismo en Argentina (y en varios países latinoamericanos) incluso se trasladó al ámbito mundial después de la crisis económica global de 2008. Sin embargo, Brenner, Peck y Theodore (2011, p. 22) sugieren, por el contrario, que: "[...] más que la sentencia de muerte para el neoliberalismo, podemos estar viendo otro punto histórico de inflexión del mutante proceso de neoliberalización".

En efecto, estos autores critican las posturas que sostienen su muerte y ponen el acento en la deficiente conceptualización del sistema regulatorio al que se denomina neoliberalismo. La noción analítica clave que ellos postulan es la de pensar al neoliberalismo como un proceso de neoliberalización y no un estado o condición final. Así, entienden que la neoliberalización es un proceso cambiante, evolutivo y plástico cuyo núcleo reside -señalan Peck y Tickell (2003, p. 166) - en "la movilización del poder estatal para extender el dominio del mercado".

Al respecto, Seoane, Taddei y Algranati (2013 p. 30), explican que en países como Brasil, Argentina y Paraguay se había puesto en marcha el proyecto neodesarrollista en los primeros años de la década del 2000. Si bien este se caracterizó por procesos de crecimiento económico con inclusión social, su aspiración a reconstruir la autoridad estatal también se destacó, como sostiene Katz (2015, p. 232), "por su tibio intento en el sostenimiento de ciertas actividades industriales". Así, la fallida experiencia, explican Fernández y Seiler (2015, p. 234), terminó por expresar el arrastre interno de las contradicciones que profundizaron su condición de economía periférica, amalgamadas bajo el CW.

En tal sentido, se trata de un síndrome, de una lógica extendida a escala global que se reproduce en lugares, territorios y escalas diversas. Según proponen Fernández y Cardozo (2012, p. 13), este síndrome encuentra su base en la reestructuración espacial y escalar del Estado y el impulso de una nueva lógica funcional que desplaza la perspectiva de bienestar del Estado hacia otra de una intervención workfarista, asociada en primer término a una implicación orientada hacia la creación de ambientes productivos dinámicos sustentados en la cualificación de la productividad laboral y la innovación empresarial. 
En línea con las ideas de la NOR, desde el 2004 se implementó en Argentina el Plan Estratégico Territorial (PET) ${ }^{21}$ coordinado por el Ministerio de Planificación Federal Inversión y Servicios Públicos, a través de la Subsecretaría de Planificación Territorial de la Inversión Pública ${ }^{22}$, en el que todas las jurisdicciones provinciales se articularon con una metodología homogénea, lineamientos e iniciativas de impacto territorial. Por su parte, el Consejo Federal de Inversiones, a través de su Línea de Trabajo sobre Planificación Estratégica Regional23, asistió y acompañó las experiencias en los municipios, junto a las provincias interesadas en la implementación de los Planes Estratégicos de Desarrollo Local (PEDL) ${ }^{24}$.

En este escenario de propagación de políticas fragmentarias, el ingreso e institucionalización de la NOR en la provincia de Formosa y sus localidades comenzó a operar entre mediados y fines de la década de 1990 a través de las primeras experiencias que Giuliano (2015, p. 147) llama el anclaje del centro-oeste y con el Bosque Modelo Formoseño (BMF) ${ }^{25}$. Es esta perspectiva de políticas la que proliferó y continuó durante el ciclo neodesarrollista-posconvertibilidad, en los ámbitos nacional y provincial.

Durante ese período, si bien se intenta posicionar con una impronta mayor al Estado, toda la dirigencia política y la burocracia incorpora el lenguaje y las políticas de gestión basadas en la NOR, como el camino inexorable para el desarrollo regional/local integrado al mundo. Ello implicó el surgimiento de espacios institucionales creados por la provincia, desde los cuales se pusieron en práctica políticas funcionales a la NOR. Se trata entonces de un conjunto de dispositivos regulativos fragmentarios de políticas que operan en las escalas regional/local del territorio a través de los programas de competitividad ${ }^{26}$,

$21 \quad$ El Plan Estratégico Territorial Formosa 2015 inició en el 2005.

22 El objetivo desde 2004 era concretar inversiones públicas y de equipamiento a través de una metodología homogénea de articulación y consensos entre organizaciones públicas, civiles y económicas. Sus diferentes etapas se extienden hasta el 2016. Es importante aclarar que desde el 2015 la subsecretaría funciona en el ámbito del Ministerio del Interior, Obras Públicas y Vivienda.

23 La entidad acompañó el financiamiento de los procesos de Planes Estratégicos de Desarrollo Local en el territorio de Formosa.

24 En Formosa el Poder Ejecutivo eligió 25 localidades donde se formularon los PEDL. Aquí se enumeran solo las de la región oeste: 1) Ingeniero Juárez, 2) General Enrique Mosconi y 3) Pozo de Maza.

25 El BMF es un concepto canadiense extendido a escala mundial, que promociona el desarrollo sustentable, opera en el oeste de Formosa en la localidad de Ingeniero Juárez. Es una asociación civil sin fines de lucro creada en 1998, con personería jurídica en 2004, integrada por una decena de instituciones (RIABM, 2010, p. 7)

26 Operan en el territorio de manera fragmentaria las siguientes: a) Estrategia Provincial para el Sector Agroalimentario (EPSA), Ministerio de la Producción y Ambiente; b) Programa de Competitividad de 
la Agencia de Desarrollo Empresarial (ADE) ${ }^{27}$, iniciaciones de clúster ${ }^{28}$, el PET Formosa 2015 y los PDEL.

Lo anterior consiste en un andamiaje de políticas fragmentarias de diferentes características y de articulación de objetivos, pero que tienen como principio rector la construcción de espacios de acumulación (EA) inspiradas en la NOR de base participativa, universal y comunitarista. Los EA son instancias de implicaciones fragmentarias público-privadas, en las que operan las estrategias de lógicas de intereses en disputa, de actores económicos, políticos y sociales junto a dispositivos regulativos fragmentarios; en estas se proyectan las ideas de movilizar los engranajes que propulsan la búsqueda del desarrollo integrado al mundo.

Hacia el interior de estos procesos territoriales local-global, los fundamentos de la NOR refuerzan el reescalonamiento espacial hacia abajo basado en la descentralización y la relativización de la escala nacional a través del PET y los PEDL. Pero también desarticula las tensiones sociales, que producen las redes del capital global e impulsan — hacia el interior de los territorios en disputa — un mensaje de construcción horizontal y participativa que promete alcanzar el desarrollo local, aunque en los hechos, termina siendo funcional a esos intereses dominantes, como se observa más adelante. Se abre con ello una nueva arquitectura regulatoria que Peck y Tickell (2007, p. 33) denominan roll out del proceso neoliberalizador, esto es, el despliegue de formas consensuadas de: "nuevos modos de regulación, nuevas formas estatales, nuevos regímenes de gobernanza, con el objetivo de consolidar y acoplar tanto la mercantilización como sus consecuencias".

En esta dinámica, en el 2004 el Estado Nacional creó la empresa Energía Argentina S.A. (Enarsa) $)^{29}$. Y en esa misma sintonía, en el 2005 Formosa imitó esta orientación con la empresa Recursos y Energía Formosa S.A. (Refsa), como se observa en la segunda parte de este trabajo.

Norte Grande (PCNG): Plan de Competitividad del Conglomerado Bovino de Formosa; c) Proyecto de desarrollo del Centro-Oeste.

27 La ADE es una institución sin fines de lucro en la cual confluyen empresarios, cámaras, universitarios, técnicos y organismos gubernamentales para desarrollar las potencialidades de la economía regional y mejorar la competitividad de las empresas. Se puede consultar al respecto en su página web: www. adeformosa.org.ar.

28 El Programa de Servicios Agrícolas Provinciales (PROSAP) articula entre sus instrumentos de implicación las Iniciativas de Desarrollo de Clúster (IDC). Se puede consultar al respecto en su página web: http:// www.prosap.gov.ar.

29 Mediante la Ley 25.943 se creó la empresa mixta con mayoría estatal cuyo propósito era el negocio energético, tanto en petróleo y derivados como en gas y energía eléctrica. El objetivo que buscaban era la participación del actor estatal en un mercado dominado por oligopolios privados, afincados durante el proceso privatizador de la década de 1990. 
Se evidencia entonces que como parte del proceso de redefinición del patrón socioeconómico espacial de acumulación a partir del nuevo paradigma tecnoproductivo flexible y de globalización, el Estado nación se transforma morfológica y funcionalmente, como también sus escalas subnacionales, pero no desaparecen.

Jessop (1994, p. 263) denomina la configuración emergente del Estado como régimen schumpeteriano de Workfare. Se trata del Estado de competencia o del Workfare que para Jessop (2008), se orienta funcionalmente a fomentar la flexibilidad, competencia e innovación, a crear, orientar y enriquecer las redes de economías nacionales y regionales, y a generar procesos de articulación supra y subnacionales.

Es esta perspectiva del Estado la que se impone en Formosa, conjugada en el MFDP. Un ambiente en el cual los policy makers que lideran las instituciones estatales en un complejo entramado regulativo median acuerdos para que las fracciones del capital (en nuestro caso analítico, en representación del interés petrolero) accedan a la liberación de un conjunto de activos como las reservas naturales del petróleo, incluida la fuerza de trabajo a un coste muy bajo. Esa dinámica regulativa es la que, a su vez, va adquiriendo -durante el tiempo espacial en estudio- nuevas características que buscan reposicionar el poder del Estado con mayor injerencia en esta actividad. Sin embargo, no modifica la atmosfera dominante extractivista-exportadora, que en términos de Harvey (2004, p. 113), desarrollan procesos de acumulación por desposesión.

Con respecto a esta configuración estatal, Peck y Tickell (1994, p. 292) señalan los límites que se generan cuando la regulación y las políticas públicas se plantean exclusivamente desde la instancia local-regional -las cuales se entregan a la dinámica del capital global móvil y a la competencia por las fracciones de capital-ya que estas, por sí solas, tienen poco poder político para conducir esos procesos en un contexto de acumulación global y desregulado. En el mismo sentido, Jessop (2008, p. 261) aporta que las instancias estatales subnacionales desprovistas de una articulación con el Estado-nación -que dispone de una base fiscal para realizar modificaciones en esos ámbitos- no pueden por sí mismas, generar transformaciones sustantivas en esas materias.

En una conclusión aún parcial, es posible expresar que la reestructuración morfológica, el desarrollo de nuevas funciones y el modo de intervención del Estado implican reacomodar la forma de organización del poder y de las relaciones entre los actores, lo que influye en la definición de sus políticas y en cómo se ejercen. Se añade a esto otro aspecto relevante: la redefinición de las funciones del Estadonación, cuya centralidad estratégica se mantiene, pero reformulada y reestructurada por la proliferación de las escalas y sus dinámicas, y readaptada a la nueva lógica de acumulación y reproducción del capital y de su impacto en los territorios. A continua- 
ción, se ofrece una profundización en estos cambios en las formas de organización e implicación estatal para abordar la dinámica de acoplamiento fragmentario de las políticas públicas productivistas que se despliegan para configurar el patrón regulativo escalar que opera en el complejo y su complementación con programas de fomento al desarrollo y los PEDL, que se pliegan a dicho patrón.

\section{EL COMPLEJO HIDROCARBURÍFERO FORMOSEÑO Y EL ESTADO DE COMPETENCIA}

Para Gorenstein (2012, p. 42), los complejos o sistemas productivos territoriales:

Son los agrupamientos productivos integrados por empresas (independientes o interdependientes) que pertenecen a una misma cadena productiva o sistema de input-output: entre ellas, las explotaciones agropecuarias, unidades industriales, comerciales. Para su abordaje se implementa el marco conceptual-metodológico de los complejos productivos regionales. Se trata de un enfoque sistémico, que permite reconocer las relaciones (mercantiles y no mercantiles) de los agentes e instituciones que lo integran, los ámbitos en los que convergen actividades conexas de diferente naturaleza y las relaciones asimétricas y de dominación propias de los procesos de reproducción del capital que se producen en estos espacios económicos-territoriales.

Desde esta perspectiva es que se estudia el complejo hidrocarburífero de la provincia de Formosa. Al respecto, la producción petrolera formoseña data de 1983 en Palmar Largo, ubicado en el departamento Ramón Lista ${ }^{30}$. Por aquellos años, el desarrollo del yacimiento significó una importante destrucción del monte nativo, con sus correspondientes efectos ambientales ${ }^{31}$ y socio-territoriales para los pequeños productores agrarios y pueblos originarios.

En este sentido, el desmonte y quema vinieron de la mano de las tareas de prospección, obras de perforación del pozo descubierto, instalación de infraestructuras, transporte y posteriores exploraciones. A ello se sumó el sobrepastoreo ganadero extensivo, sobreexplotación de recursos forestales e incendios producidos por la sociedad que convirtieron el espacio en uno gravemente amenazado debido a sus condiciones ambientales semidesérticas.

Por otra parte, hay que señalar el impacto social del desarrollo petrolero. La instalación de los pozos de petróleo significó un aumento de la población, según

$30 \quad$ "La búsqueda de petróleo por parte de YPF en Formosa se remonta a la década de 1960, con perforaciones en Pirané y Mariano Boedo, ciertamente sin éxito [...], en diciembre de 1983, las principales unidades operativas de YPF se asentaron en la localidad de Palmar Largo donde el pozo descubierto XI, comenzará a producir 600 metros cúbicos" (Gorleri, 1996, pp. 3-5).

31 Según Gorleri (1996, p. 16): "La primera etapa de los estudios exploratorios se realizaron en una superficie que superaba el millón de hectáreas.|..., que implicó su desmonte y posterior quema del mismo. El daño forestal, fue de unos 244 millones de dólares, en un ambiente [quel considero frágil debido a su dinámica ambiental, caracterizado por las altas temperaturas, salinidad y aridez de sus suelos que dificultan la capacidad reproductiva del monte". 
el Censo Poblacional de 1991 se dio un 66 \% de incremento, siendo mayoría la población originaria (Instituto Nacional de Estadísticas y Censos, 1991). Dicha población se vio atraída por la ampliación de la infraestructura y los servicios del Estado (educación y salud) y la promulgación de la Ley Integral del Aborigen ${ }^{32}$, la cual distribuía las tierras a las comunidades e institucionalizaba la representación de los pueblos originarios en la estructura del Estado, pero que también las burocratizaba y sometía al empleo público como agentes sanitarios, auxiliares docentes o bien con cargos político-administrativos en el Instituto de Comunidades Aborígenes (ICA) y sus delegaciones.

Sin embargo, dicha población no fue beneficiaria del acceso a puestos de trabajo en el complejo petrolero que permitieran mejores condiciones de vida. Por el contrario, la continuidad de una modalidad productiva hidrocarburífera extractivista-exportadora fue el motor de tensiones sociales, las que a través de las denominadas estrategias de la NOR de fomento al desarrollo, intentaron contenerse con programas de micro-emprendimientos de artesanía aborigen o actividades alternativas para pequeños productores criollos, implementadas por organizaciones no gubernamentales (ONG), algunas de ellas financiadas por organismos supranacionales, o bien creadas por las empresas petroleras y las iglesias anglicanas y en las que la institucionalidad articulada con el Estado, al realizar complejas y diversas mediaciones con los actores representativos de esas lógicas de intereses ${ }^{33}$, no impidieron que operaran procesos de acumulación extractiva-exportadora.

Palmar Largo es el yacimiento más importante de la provincia, tras ser operado por YPF durante la década de 1980, en 1992 -como anticipamos- se activó la regulación a favor de los capitales extranjeros y nacionales, se habilitó la privatización y provincialización del yacimiento, lo que permitió el avance del capital cuya estructura productiva petrolera quedó conformada, como detalla Reynals (2005a, p. 8), con: YPF (30\%), Pluspetrol (20,3\%), Compañía General de Combustible (CGC) $)^{34}$

32 La Ley 426 creó el Instituto de Comunidades Aborígenes (ICA) y autorizó la conformación de sus delegaciones como centros comunales, encargados de atender las necesidades económicas, sociales, de educación, trabajo, salud y vivienda. Se propuso encarar toda planificación bajo tres aspectos: organización, participación y capacitación aborigen (art. 26).

33 Para un análisis detallado de estos procesos véase el trabajo de Braticevic (2009).

34 La Compañía General de Combustible (CGC) era propiedad de Sociedad Comercial del Plata, de Santiago Soldati. Esa compañía vendió en 2003 el 81 \% de la petrolera, que por entonces facturaba 70 millones de dólares entre Argentina y Ecuador. El comprador fue el fondo de inversión Southern Cross, que para ingresar en la compañía se hizo cargo de la totalidad del pasivo de 200 millones de dólares. El 19 \% restante siguió en manos de Comercial del Plata. En el 2013, Eurnekian compró la firma y se quedó con casi el 81 \% de CGC por unos 200 millones de dólares, con 16 áreas en Santa Cruz, Neuquén, Río Negro, Salta, Formosa y Venezuela (Redacción Río Negro, 2013). 
$(17,85 \%)$, Norcen (17,85 \%) y la sur coreana Dong Won (14\%). Posteriormente, Pluspetrol compró el porcentaje de Norcen y obtuvo la mayoría de las acciones del yacimiento.

Gráfico 1: Formosa: cuenca de hidrocarburos del noroeste

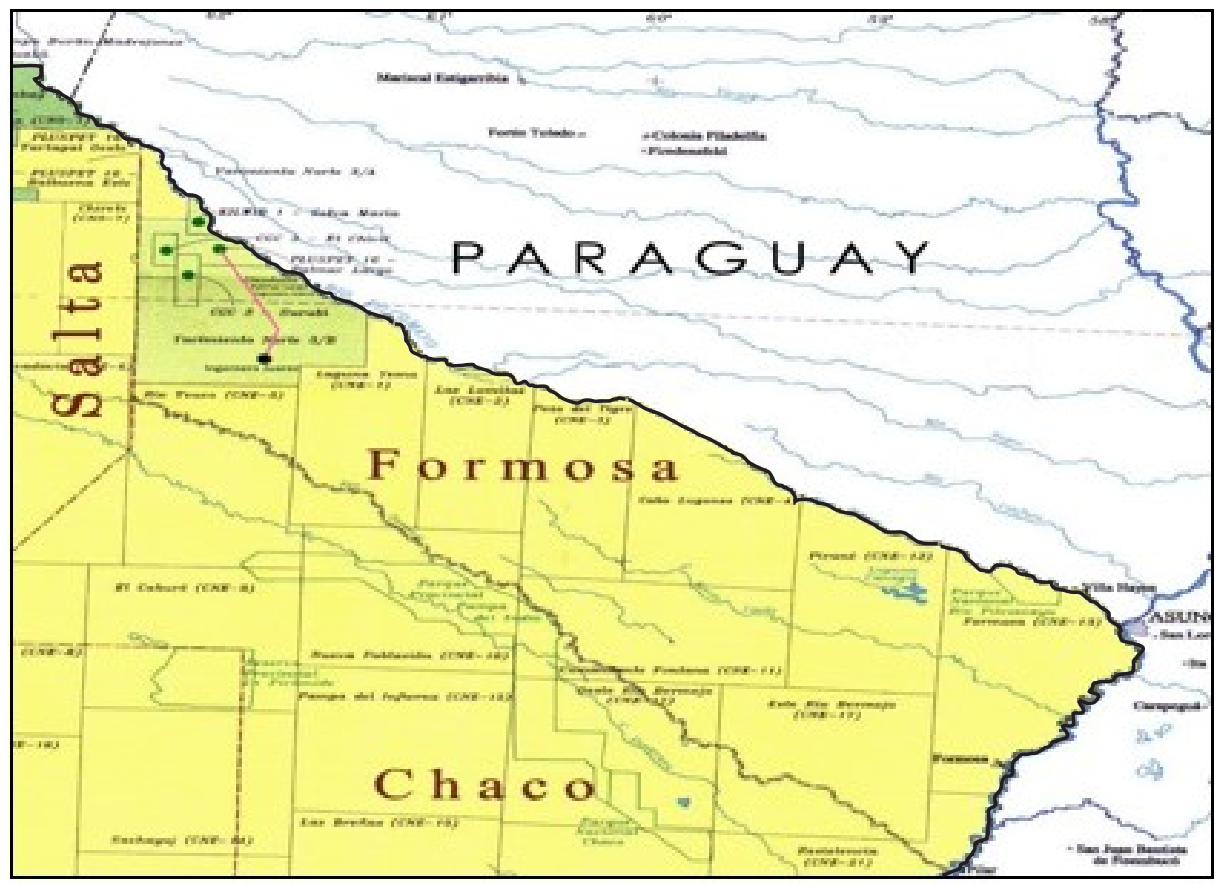

Referencia:

Oleoducto Palmar Largo-Ingeniero Juárez

Pozos de hidrocarguros: Palmar Largo; Chivil

Surubí y Selva María

Localidad de Ingeniero Juárez

Cuenca de hidrocarburos noroeste, Formosa

Áreas transferidas a Formosa sin concesión

Fuente: elaboración propia según datos de la Subsecretaría de Planeamiento Energético (2015)

Es decir, se trata de un período en el que el funcionamiento del patrón regulativo escalar neoliberalizador configurado permitió el dominio del capital privado de origen internacional y nacional en la explotación, ventas internas y externas, cuyo impacto en la región no se vincula con la obtención directa de mayores niveles 
de regalía ${ }^{35}$ para la provincia y el mejoramiento de las condiciones de vida de la población del Oeste.

Durante los primeros años de producción, señala Reynals (2005a, p. 14), lo cual se puede apreciar en el gráfico 1, el crudo se transportaba a través de un oleoducto a la localidad de Ingeniero Juárez y desde allí, una parte se trasladaba por tren a la refinería de Refinor en la provincia de Salta, otra parte iba a la ciudad de Formosa para su exportación. Ese proceso se hizo continuo y se profundizó hacia finales de la década de 1990 e inicios del nuevo siglo. Esto último se puede observar claramente en la tabla 1 .

Tabla 1. Exportaciones de Formosa por grandes rubros en millones de dólares y en porcentaje (1998-2002)

\begin{tabular}{|c|c|c|c|c|c|c|c|c|c|c|}
\hline Fecha & \multicolumn{2}{|c|}{$\begin{array}{c}\text { Total en } \\
\text { millones de U\$S } \\
\text { y porcentaje (\%) }\end{array}$} & \multicolumn{2}{|c|}{$\begin{array}{c}\text { Productos } \\
\text { primarios en } \\
\text { millones de U\$S } \\
\text { y porcentaje (\%) }\end{array}$} & $\begin{array}{c}\text { Manufacturas de } \\
\text { origen agropecuario } \\
\text { (MOA) en millones } \\
\text { de U\$S y porcentaje } \\
\text { (\%) }\end{array}$ & $\begin{array}{c}\text { Manufacturas de } \\
\text { origen industrial } \\
\text { (MOI) en millones } \\
\text { de U\$S y porcentaje } \\
\text { (\%) }\end{array}$ & \multicolumn{2}{|c|}{$\begin{array}{c}\text { Combustibles y } \\
\text { energía: petróleo } \\
\text { crudo en millones de } \\
\text { U\$S y porcentaje (\%) }\end{array}$} \\
\hline 1998 & 29,8 & 100 & 19 & 64 & 1 & 3,4 & 1 & 3,4 & 9 & 32,2 \\
\hline 1999 & 20,6 & 100 & 9 & 45 & 0 & 0 & 1 & 4,8 & 10 & 48,5 \\
\hline 2000 & 14,2 & 100 & 2 & 14 & 0 & 0 & 1 & 7 & 12 & 84,5 \\
\hline 2001 & 16,7 & 100 & 3 & 18 & 0 & 0 & 1 & 6 & 12 & 71,8 \\
\hline 2002 & 17,8 & 100 & 3 & 17 & 1 & 5,6 & 0 & 0 & 14 & 79.5 \\
\hline
\end{tabular}

Fuente: elaboración propia según datos del Indec (2002)

Así las cosas, mientras caía la participación en las exportaciones de los productos primarios y las manufacturas de origen agropecuario e industrial, el petróleo crudo aumentaba y adquiría una preponderancia superlativa creciente desde 1998, en el 2000 representaba ya más de un 80 \% de las exportaciones y en el 2002, un $79,5 \%$.

35 En el momento en el que se provincializaron los yacimientos, estas escalas estaduales agrupadas en la Organización Federal de Estados productores de Hidrocarburo (OFEPHI), en la cual participa Formosa, comenzaron un proceso de reclamos y presentaciones de proyectos de Ley que hacían hincapié en modificar las formas de control y liquidación de las regalías por la explotación del petróleo que hacían las compañías privadas. Ese reclamo se dilató en el tiempo y generó que algunas provincias iniciaran un reclamo judicial al Estado Nacional. En 1999 la OFEPHI firmó un tratado ad referéndum de sus poderes legislativos respectivos, para que le otorgaran jerarquía de Tratado Interprovincial en los términos del artículo 124 de la Constitución Nacional, debido a la pérdida de estado parlamentario del primer anteproyecto de Ley de Hidrocarburos, que había logrado la media sanción del Senado y la frustración de los sucesivos anteproyectos redactados con la participación provincial, los cuales tampoco lograron sanción (OFEPHI, 2019, p. 1-9). 
Esto datos elocuentes -que acercan a esa lógica acumulativa extractivistaexportadora- también se vieron beneficiados por la decisión de provincializar los yacimientos petroleros, ya que lo aprovecharon las fracciones del capital petrolero a través de estrategias que permitieron dilatar y frenar durante esta etapa la posibilidad de que las provincias -entre ellas Formosa-accedieran a mejores regalías petroleras.

Entre 2003 y 2012 el proceso neoliberal fue abigarrado en la experiencia neodesarrollista, de modo que el complejo presentó continuidades heredadas de la etapa anterior. Es decir que el patrón regulativo escalar de la década de 1990, caracterizada por una regulación a favor de los capitales nacionales y extranjeros, privatizaciones y su provincialización, aquí no desaparecieron de manera radicalizada, sino que se abigarraron con elementos regulativos de su predecesor. Así, las políticas puestas en marcha en su intento de reconfiguración del Estado a escala nacional y provincial en la actividad petrolera no logró romper con el dominio de los actores privados del sector, que prosiguieron con su acumulación basada en la extracción y el destino exportable.

En este sentido, con la creación de Refsa en Formosa en $2005^{36}$ se inició un camino de negociaciones con los capitales privados extranjeros que le permitió hacia el 2007, participar en dicho mercado, en un contexto en el que el gobierno nacional-cinco años después- tomó la decisión de nacionalizar la principal empresa productora de petróleo de Argentina: Yacimientos Petrolíferos Fiscales (YPF).

En efecto, a partir del proceso desregulatorio y privatizador iniciado en 1992 -como argumenta Reynals (2005a, p. 18)-, el impacto directo fue una explotación persistente con caída en la producción petrolera provincial debido a la disminución de las reservas en la principal área de petróleo de Formosa que se prolongó hasta el 2011, su principal destino fue la exportación.

Estas tendencias significativas que revelan la caída en producción petrolera de la principal reserva de Formosa -Palmar Largo- se pueden observar en el gráfico 2. A su vez, a escala regional/local -como bien demuestra Giuliano (2019, p. 147-269)- la producción hidrocarburífera evidencia nula articulación con los demás sectores de la producción local, entre las que se hallan la ganadería y la producción forestal, realizada por pequeños productores criollos e indígenas de este espacio territorial.

36 La empresa Refsa, fue creada mediante la Ley $\mathrm{N}^{\circ} 1.469$, con el objetivo de explorar y explotar áreas no concesionadas; generar transporte, distribución y comercialización de la energía eléctrica y de servicios de telecomunicaciones. Refsa, resulta ser un símil de Enarsa, en materia hidrocarburífera, aunque Refsa nace como consecuencia de la crisis y vaciamiento de la distribuidora eléctrica Edefor S.A., que pertenecía al Grupo Iatte S.A. Giuliano (2010). 
Gráfico 2. Producción de petróleo de la provincia de Formosa, período 1985 - 2012 en m³

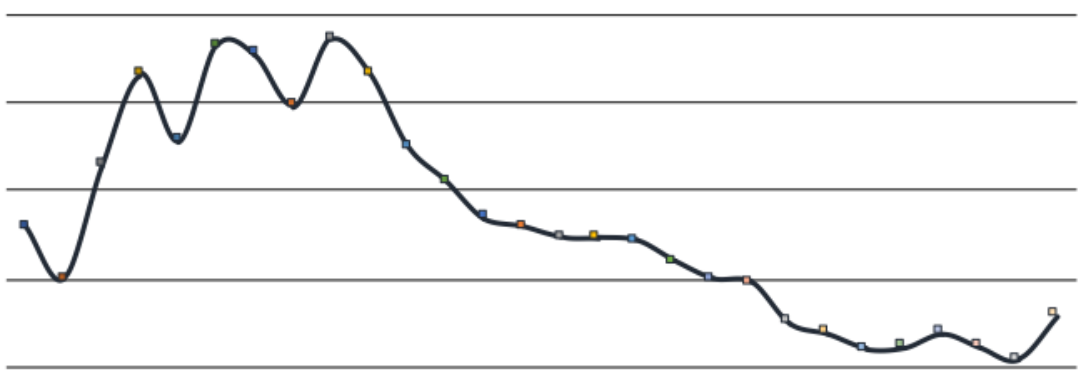

Fuente: Consejo Federal de Inversiones (CFI) 2012

Por otra parte, la provincia de Formosa cuenta además con una segunda y un tercer área adicional de exploraciones y producción, ambas ubicadas -como la primera- en la cuenca Cretácica ${ }^{37}$ del noroeste, tal como figuran en el mapa del primer gráfico: El Chivil y El Surubí.

Gráfico 3. Producción anual en $\mathrm{m}^{3}$, concesión El Chivil a Gran Tierra Energy Inc., (2006-2012)

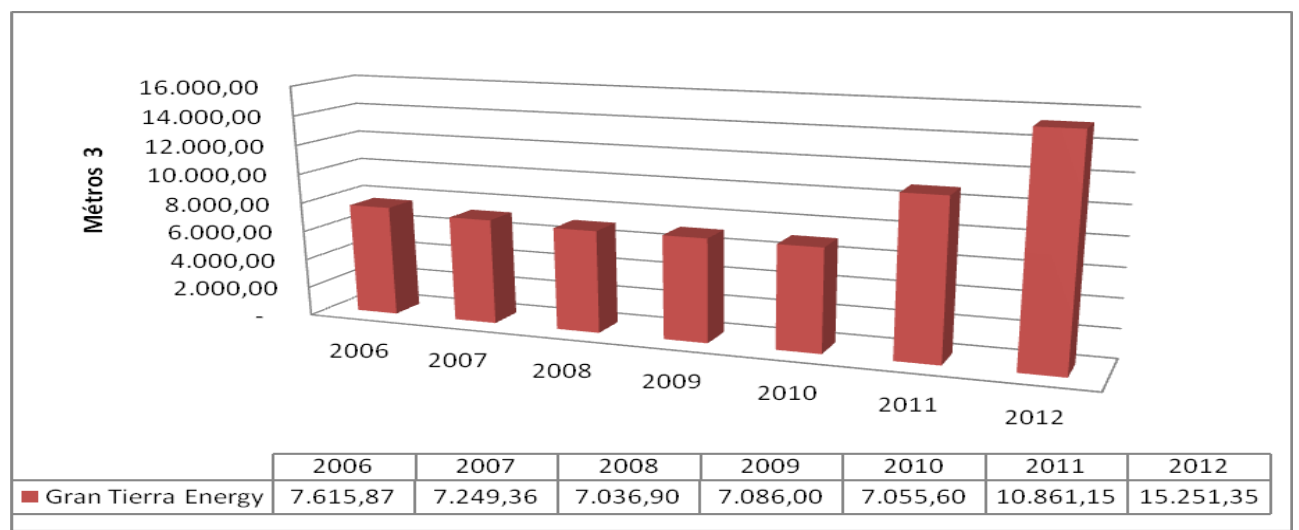

Fuente: elaboración propia según los datos la Secretaría de Energía de Argentina, 2006-2012.

El primero ocupa una superficie de $290 \mathrm{~km}^{2}$ y se ubica al sudoeste de Palmar Largo, la cantidad de pozos y su producción resultan ser notablemente inferiores al principal yacimiento. En 1990 -señala Reynals (2005b, p. 8)- el Chivil fue adjudicado en partes iguales ( 25 \% cada una) a cuatro empresas: Compañía General de

37 La cuenca atraviesa las provincias de Catamarca, Tucumán, Salta, Jujuy y el departamento Ramón Lista en el oeste de Formosa. 
Combustibles (CGC), Benito Roggio, Tecnicagua y Dong Won, su producción en el 2000 -luego de estar inactivo el año anterior- fue de $1.492 \mathrm{~m}^{3}$ por mes, para luego estabilizarse en 2003 en $700 \mathrm{~m}^{3}$ por mes. En 2004 el único pozo activo del área producía $20 \mathrm{~m}^{3}$ diarios. El Observatorio Petrolero Sur (2013, p. 4) señala que en 2006 la empresa canadiense Gran Tierra Energy adquirió la totalidad del yacimiento.

Desde entonces, como se puede observar en la gráfica, el nivel de producción se mantuvo estable hasta 2010, incrementó luego en un 54 \% en 2011 con respecto al año anterior y en un $40 \%$ en 2012.

Gráfico 4. Producción anual en $\mathrm{m}^{3}$ de la concesión El Suribí a la Unión transitoria de empresas (2007-2012)

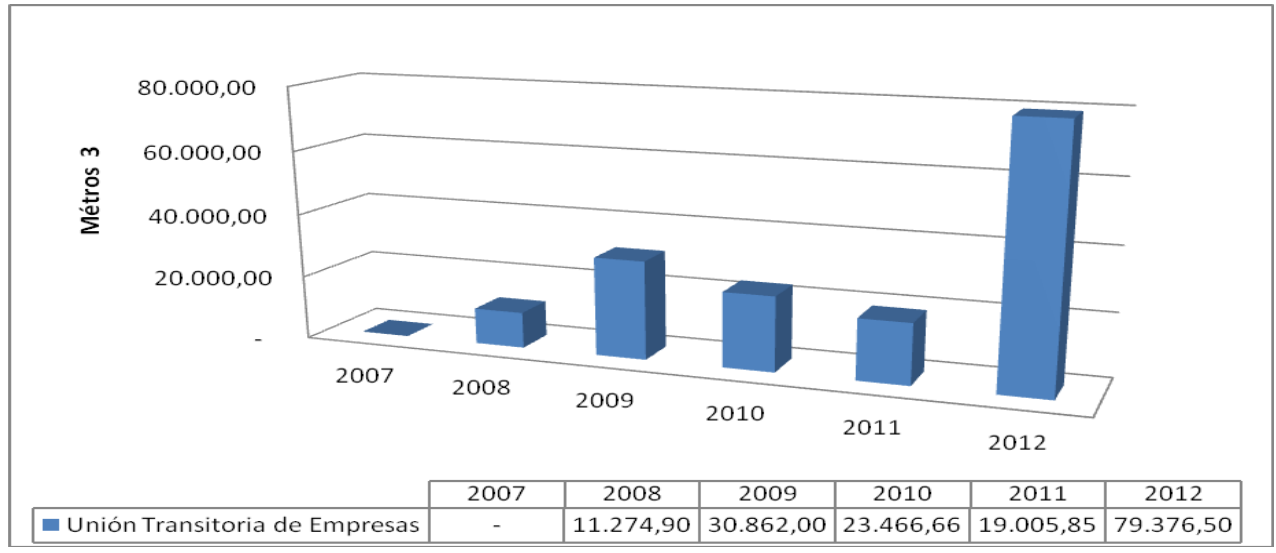

Fuente: elaboración propia según los datos de la Secretaría de Energía de Argentina, 2007-2012

Así, a partir de estos niveles de producción en El Chivil y el continuo proceso de caída de la producción y extracción para las exportaciones, fundamentalmente de Palmar Largo, las empresas privadas comenzaron a desarrollar la exploración y perforación en 2006, en el paraje El Surubí (tercer área) -que tiene una superficie de $368 \mathrm{~km}^{2}$ y se ubica a $12 \mathrm{~km}$ de la segunda área-con el nuevo marco regulatorio, como se plantea seguidamente. Esa regulación es la que permitió que se introdujeran las provincias y avanzaran en este negocio.

En efecto, la empresa Refsa incursionó por primera vez, asociada con el capital privado, en la actividad petrolera. Así, en el 2007 el área El Surubí se concesionó a la Unión Transitoria de Empresas integrada por Gran Tierra Energy, que participa con el $85 \%$ del total producido y la empresa Refsa, con el $15 \%$. Si bien hasta el 2007 el pozo descubierto en la zona no estaba en producción, en el 2008 inició su explotación con la producción de 11.274,9 m³. 
Luego de algunos altibajos, en el 2012 alcanzó la producción más alta desde su concesión, con 79.376,5 m³ , ello debido a que a partir de abril de dicho año se avanzó en la perforación y explotación de un segundo pozo (Diario El Comercial, 2012), con lo cual se comenzó a revertir la tendencia decreciente, como se observa en la gráfica de evolución de la producción de petróleo. De esta manera, inició un proceso en el cual, si bien el conglomerado de empresas privadas siguió siendo dominante en la provincia de Formosa, la decisión del Estado a través del consorcio Refsa fue participar del negocio asociados a una fracción de los capitales petroleros.

Se trata de la primera experiencia en la cual la empresa mixta se incorpora como socia de las actividades que implican la exploración y explotación del petróleo. Ello resulta de la apertura que brindó la Ley 26.197 al respecto, que transfirió los permisos de exploración, concesiones de explotación de hidrocarburos y transporte localizadas en ellas a las provincias con áreas petroleras, así como la habilitación a exigir el pago de regalías - un reclamo de la OFEPHI que se había dilatado hasta el 2006-. Esa nueva regulación les permitió, en adelante, realizar estudios para la exploración y explotación de los yacimientos provinciales que aún no habían sido permisionados.

Si bien la empresa Refsa tiene como propósito el control estratégico y la intervención sobre los recursos naturales que constituyan fuentes de energía según la Ley de creación de la firma, solo ha logrado iniciar su participación en la exploración/explotación asociada con el capital privado. Proyecta en un escenario futuro, el direccionamiento a mediano plazo de una alianza con Enarsa que promueva inversiones privadas en las diferentes áreas hidrocarburíferas de la provincia que no se hallan concesionadas.

Al respecto, se han transferido quince áreas a la provincia (ver mapa del gráfico 1): Laguna Yema, Las Lomitas, Pozo del Tigre, Cabo Lugones, río Teuco, Nueva Población, Comandante Fontana, Pirané, Formosa, oeste río Bermejo, río Bermejo, Resistencia, Yacimiento Norte 3 B, Selva María y Surubí.

Simultáneamente y en un contexto en el cual la producción de petróleo nacional disminuía, el 4 de mayo de 2012 se nacionalizó la empresa Repsol-YPF (Yacimientos Petrolíferos Fiscales) S.A. a través de la Ley 26.741, decisión que expropió el 51 \% de las acciones clase D de la empresa Repsol, las dividió en un 26,03 \% para el Poder Ejecutivo Nacional y $24,99 \%$ para las provincias productoras, estas, a su vez, firmaron un pacto de sindicación por 50 años para votar siempre juntas y asegurar el control estatal. No obstante, la empresa continúa siendo una sociedad anónima. De modo que el 25,46\% de las acciones continúa en manos del Grupo Petersen, el 6,43 \% a favor de Repsol y el 17,09\% remanente se comercializa en el mercado de valores. 
Gráfico 5. Participación porcentual de Formosa en la producción petrolera de Argentina realizada por YPF

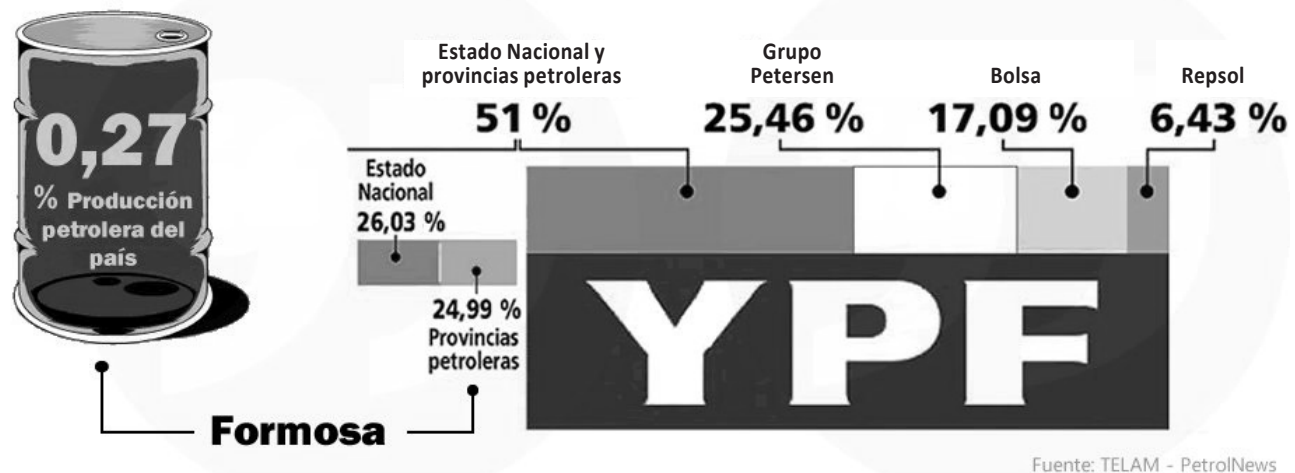

Fuente: Agencia Nacional de Noticias (Telam), PetrolNews (2012)

La ley también contempla la expropiación -en los mismos términos-de YPF GAS, otra firma que estaba en manos de Repsol. En ese escenario, Formosa participaba con un peso relativo marginal en el volumen de producción nacional al igual, que en el porcentaje a las provincias (como se observa en la infografía del gráfico 5) con un $0,27 \%$.

Hacia el final del 2012, aun con una mayor impronta relativa del Estado en ambas escalas, su dinámica decantó en la continuidad de una lógica productiva extractivista-exportadora, desencajada del resto de las actividades productivas y de las necesidades de la población local-regional, elementos estructurales persistentes durante el período analítico.

Tabla 2. Exportaciones de Formosa, en la región NEA (Nordeste argentino) y en el total del país, expresados en millones de dólares y porcentaje para el 2012.

\begin{tabular}{lccc}
\hline \multicolumn{1}{c}{ Conceptos } & Formosa & Región NEA & Total del país \\
\hline Valor total en millones de dólares & 45 & 1.030 & 80.927 \\
\hline Composición en porcentaje & & & \\
\hline Productos primarios & 29,0 & 50,6 & 23,5 \\
\hline Manufactura de origen agropecuario (MOA) & 37,8 & 33,4 & 33,9 \\
\hline Manufactura de origen industrial (MOI) & 5,3 & 14,8 & 34,0 \\
\hline Energía y combustibles & 27,9 & 1,2 & 8,5 \\
\hline Total & 100,0 & 100,0 & 100,0 \\
\hline
\end{tabular}

Fuente: Dirección Nacional de Relaciones con las Provincias (Dinrep) (2012). 
De los 45 millones de dólares exportados por la provincia de Formosa -un $0,05 \%$ del valor total exportado por todo el país y 4,4 \% en la región NEA-, uno de los rubros de importancia es el de energía y combustibles, registra la venta de petróleo crudo, explica el 27,9 \% del total de ventas al exterior. En tanto que las manufacturas de origen industrial participan con un porcentaje muy por debajo de aquel, con un 5,3\%; las manufacturas de origen agropecuario lo hacen con un $37,8 \%$ y los productos primarios con un $29 \%$.

Ahora bien, este modo de producción de las empresas se continuó traduciendo en tensiones sociales con las poblaciones originarias de mayoría elocuente en el departamento Ramón (Bauman, 2013, p. 22), producto de las desigualdades estructurales que padecían para el acceso a servicios básicos, como electricidad o agua.

Esos reclamos se asistieron desde la misma lógica operacional dinamizada por las estrategias de fomento al desarrollo, pero se profundizaron en este ciclo con la institucionalización del Plan Estratégico de Desarrollo Local (PEDL) de la Municipalidad de General Mosconi (El Chorro), ciudad cabecera ${ }^{38}$ del departamento con la mayor reserva petrolera provincial.

En este sentido, el PEDL dedicó un apartado en su propuesta de construcción colectiva con las fuerzas sociales locales en el que se compilan las principales necesidades de la población local. Ese apartado denominado "qué queremos"39 alude a la persistencia de necesidades estructurales básicas de la población local. Así, se reconoció en el PEDL (2013, p. 86) la dependencia directa de los capitales privados petroleros que suministran a la central eléctrica y del gas comprimido a la localidad de Palmar Largo para que la ciudad funcione. Desde lo productivo-laboral y como estrategia de contención, se apela en el PEDL (2013, p. 113) al asociativismo de los pequeños productores y a la implementación de programas sectoriales (de empleo, micro-emprendimientos y programas del Ministerio de Trabajo, Empleo y Seguridad Social de la Nación), en línea con los seguidos y financiados por organismos supranacionales o las propias empresas petroleras ${ }^{40}$.

38 Esta condición surge del hecho de que es la única reconocida políticamente como municipio por el gobierno provincial (PEDL, 2013, p. 22).

39 Se reiteran allí, el problema de escasez de agua, su acceso para las comunidades, la extensión eléctrica, finalización de caminos troncales, escuelas y hospitales (PEDL, 2013, pp. 29-30).

40 Entre los organismos multilaterales que ingresan al territorio, se hallan el Dirli de la Comunidad Europea que operó entre 1997 a 2002 en Ramón Lista con programas de viviendas y el Grupo de Apoyo a Emprendimientos Productivos en Comunidades Marginadas, financiado por la petrolera Pluspetrol (Braticevic, 2009). 


\section{CONCLUSIONES}

Se observa que el patrón regulativo escalar de la fase neoliberal, que se consolidó en la década de 1990 a través de las reformas estructurales y la retracción del Estado, se combinó con el roll out para vehiculizar la continuidad y la reelaboración del proceso neoliberal a través de la plataforma común de la NOR. Una lógica de coproducción de políticas con los actores regionales que imponen una extensión de los procesos de mercantilización a través de una implicación estatal que facilita un renovado y más complejo proceso de desarticulación fragmentante y abigarrada al momento de implicar la dinámica regional. El complejo hidrocarburífero de Formosa muestra concretamente el despliegue de esta intervención.

En esa dinámica, el acoplamiento de las políticas públicas productivistas fragmentarias en el complejo estudiado revelan la puesta en juego de un conjunto de dispositivos regulativos fragmentarios, en el marco de la configuración de arreglos escalares verticalizantes y hegemónicos, que se consolidan y median estrategias con actores diversos, representativos de las fracciones del capital petrolero, cuya participación cambiante -en el sentido de no ser siempre las mismas empresas las que explotan el petróleo- trazan una caracterización del espacio de acumulación con elementos que marcan la selectividad de las políticas públicas, tensiones y disputas por los recursos naturales.

Estos procesos, al estar institucionalizados con arreglos escalares verticalizantes y hegemónicos a través de políticas desarticuladoras y fragmentarias, generan un profundo proceso de reestructuración escalar del Estado, funcional para la reproducción neoliberal y sus nuevas formas de mercantilización y subordinación. De allí que en contextos periféricos como los de Formosa, resulta imprescindible conocer cómo opera dicho proceso, ya que no se conoce cuál es el papel que juegan las escalas al estar ausente del aparato discursivo de la NOR y en consecuencia, tampoco existe una centralidad puesta sobre el papel del Estado en dicha plataforma común.

Así, esa lógica desarticulada y fragmentaria que domina la implicancia estatal formoseña es la que contribuye a mantener inalterado el perfil del EA como extractivista-exportador. De esa manera, el patrón regulativo escalar fragmentante, cuando opera, se acopla con mediaciones que han contribuido a no alterar de manera radical las condiciones regulativas favorables a las fracciones de los capitales hidrocarburíferos que dominan el territorio, en detrimento de sus pobladores, que continúan afectados en necesidades básicas insatisfechas, largamente reclamadas. 


\section{REFERENCIAS}

Agencia Nacional de Noticias-TELAM-PetrolNews (2012). "Participación porcentual de Formosa en la producción petrolera de Argentina realizada por YPF-Yacimientos petrolíferos fiscales". Buenos Aires. Argentina, p. 1.

Amín, Samir (1998). El capitalismo en la era de la globalización. Barcelona, España: Paídos, 296p.

Arrighi, Giovann y Silver Baverli (2001). Caos y orden en el sistema-mundo moderno. Rio de Janeiro, Brasil: Contraponto Editora, 328p.

Azpiazu, Daniel, Manzanelli Pablo, y Schorr Martín, (2011). Concentración y extranjerización la Argentina en la posconvertibilidad (2002-2008), En: Cuadernos del Cendes, Vol 28, № 76 , p. 97-119.

Bauman, Zygmunt (2012). Los campos de exterminio de la desigualdad. Ciudad de México, México: Fondo de Cultura Económico, 233p.

Becattini, Giacomo (1992). Le district industriel. En: Espaces et sociétés, No.66-67, p.143-147.

Benko, Goerges y Alain Lipietz (1994). Las regiones que ganan: distritos y redes. Los nuevos paradigmas de la geografía económica. Valéncia, España: Alfons el Magnànim, 400p.

Braticevic, Sergio, (2009). ONGS para la Metamorfosis de los modelos evangelizadores en el Chaco Central. Los desarrollos y su Razón Intervencionista en un espacio de Expansión reciente. En: Papeles de Trabajo N. ${ }^{\circ}$ 17. Centro de Estudios Interdisciplinarios en Etnolingüística y Antropología Socio-Cultutal. Universidad de Buenos Aires, p.1-13.

Brenner, Neil; Peck, Jamie y Theodore, Nik, (2011). ¿Y después de la neoliberalización? Estrategias metodológicas para la investigación de las transformaciones regulatorias contemporáneas. En: Urban. NS01 Artículos y notas de Investigación, p. 21-40.

Cooke, Philip y Kevin, Morgan (1999). The Associational Economy: Firms, Regions, and Innovation. Oxford, UK: Oxford University Press, 247p.

Diario El Comercial (2012). Hallaron Petróleo en Ramón Lista. Interior, Formosa, Argentina, 1p.

DINREP-Dirección nacional de relaciones con las provincias (2012). "Informe Formosa". Ministerio de Economía de la Nación. Buenos Aires. Argentina, p. 1-20.

Fajerberg, Jan (1998). The Associational Economy: Firms, Regions, and Innovation. Philip Cooke and Kevin Morgan (Eds.), Oxford University Press, Oxford, 1999, 247 pp., £42.50/£14.99, ISBN 019-829018-7 En: Research Policy, Vol. 32, No. 6, p. 1146-1148. Doi: 10.1016/S00487333(02)00123-3.

Fernández, Víctor Ramiro, Amin, Ash, y Vigil José, (2008). Repensando el Desarrollo Regional. Contribuciones globales para una estrategia latinoamericana, Buenos Aires. Miño y Dávila, 557p.

Fernández, Víctor Ramiro y Cardozo Lucas Gabriel (2012). Nueva Estatidad bajo la Reemergencia Regional. La reelaboración del proyecto neoliberal y sus alteraciones en la periferia, En: Revista Brasileira de Estudios Urbanos e Regionais, Vol. 14, №2, p. 11-33. 
Fernández, Víctor Ramiro y García Puente, María Jimena, (2010). Transformaciones Estatales ¿Cambio en sus funciones? Revisando perspectivas teóricas para analizar el Estado contemporáneo, En: Revista de la Facultad de Ciencias Jurídicas y Sociales, Vol. 1, № 8, p. 137-148.

Fernández, Víctor Ramiro; Seiler, Cristhian Rubén (2015). Procesos de acumulación, industria y Pyme. El caso argentino y los límites del neodesarrollismo, En: Revista Sociedad y Economía, $\mathrm{N}^{\circ} 30$, p. 225-253.

Fernández, Víctor Ramiro; Vigil, José Ignacio y Seval Martín (2012). Explorando la Región. Territorios, escalas y relacionalidades. En: Revista de Geografía Norte Grande, N 51, p. 21-41. Doi: http://dx.doi.org/10.4067/S0718-34022012000100002

Giuliano, Ernesto Fabián (2010). La energía Eléctrica en la Provincia de Formosa - Período 1994-2007: Un análisis de la Morfología de Mercado. En: XIII Jornadas de Ciencia y Tecnología. Formosa: Argentina: Universidad Nacional de Formosa, p. 1-25.

Giuliano, Ernesto Fabián (2015). Sociedades Periféricas y Multiterritorios. Análisis de la estructura social de Formosa en el ciclo 1980-2002. Buenos Aires: Argentina: La Colmena, 350 p.

Giuliano, Ernesto Fabián (2019). Los cambios a nivel funcional y espacial del Estado y la Estructura productiva territorial formoseña. Tesis para el Doctorado en Ciencias Sociales. Programa de Doctorado. Buenos Aires: Argentina: Universidad de Buenos Aires, 446 p.

González, Sara (2005). La geografía escalar del capitalismo actual. En: Geo Crítica / Scripta Nova. Revista electrónica de geografía y ciencias sociales. Vol. IX, $\overline{N^{\circ}} 189$, p. 1-26.

Gorenstein, Silvia, (2012). Acumulación y desarrollo regional. Discusiones, enfoques y temas sobre la experiencia del norte argentino, En: Silvia Gorenstein (org.) ¿Crecimiento o Desarrollo? El ciclo reciente en el norte argentino. Buenos Aires, Argentina: Miño y Dávila, 207p.

Gorleri, Carlos (1996). Auditoría del impacto ambiental de la actividad petrolera en el Oeste de la Provincia de Formosa. Monografía para la Maestría en Gestión Ambiental y Ecológica. Facultades de: Arquitectura y Urbanismo,Ciencias Exactas y Naturales. Universidad Nacional del Nordeste (UNNE), Corrientes, Argentina, 25p.

Harvey, David (2004). El nuevo imperialismo: acumulación por desposesión En: Panitch, Leo, Leys, Colin Socialist Register El nuevo desafío imperial. Buenos Aires: Argentina: Clacso, p. 99-129.

HCD-Honorable Cámara de Diputados de la Provincia de Formosa (1991). Constitución Provincial de Formosa del año 1991. Preámbulo constitucional. p.1

Instituto Nacional de Estadísticas y Censos-Indec- (1991). Censo Nacional de Población y Vivienda. Buenos Aires, Argentina: Indec.

Jessop, Bob (1994). Post-fordism and the state, En: Ash Amin (ed.) Post-Fordism. Nueva Jersey, Estados Unidos: Jhon Wiley \& Sons, p. 251-279.

Jessop, Bob (2008). El futuro del Estado Capitalista. Madrid, España: De la Catarata, 374p.

Jessop, Bob (2010). What follow neo-liberalism? The deepening contradictions of US domination and the struggle for a new global order. En: Robert Albritton, Bob Jessop \& Richard Westra (eds.) Political economy and global capitalism. The 21st century, present and future. London, UK: Anthem Press, p. 67-88. 
Katz, Claudio (2015). ¿Qué es el neodesarrollismo? una visión crítica. Argentina y Brasil. En: Serviço Social y Sociedade, N 122. p. 224-249. https://doi.org/10.1590/0101-6628.021

Legislatura de Formosa (2003). Constitución Provincial de Formosa. Formosa, Argentina: Legislatura de Formosa.

Lipietz, Alain (1994). El posfordismo y sus espacios. Series Seminarios de Investigación Intensivos. En: Documento de Trabajo N 4, Piette-Conicet. Buenos Aires, Argentina: Facultad de Ciencias Económicas de la Universidad de Buenos Aires, p. 1-52.

Norodowsky Patricio y Merino Gabriel (2015). La agudización de las tensiones globales. Análisis de la crisis del orden unipolar y los conflictos geoestratégicos desde una perspectiva centro-periferia. En: Estudios Socioterritoriales $N^{\circ}$ 18. p. 81-99.

Observatorio Petrolero Sur (2013). Formosa y las quimeras del oro negro. Argentina: Observatorio Petrolero Sur. p.1-9.

OFEPHI (Organización Federal de Estados Productores de Hidrocarburos) (2019), Historia, Argentina: OFEPHI. p.1-9.

Peck, Jamie y Tickell, Adam (1994). Searching for a New Institucional Fix: the After-Fordist Crisis and the Global-Local Disorder. En: Ash Amin (ed.) Post-Fordism. Nueva Jersey, Estados Unidos: Jhon Wiley \& Sons, p. 280-315.

Peck, Jamie y Tickell, Adam (2003). Making global rules. Globalization or neoliberalization? En: Jamie Peck y Henry Wai-chung Young (eds.) Making the global economy. London, UK: Sage, p. 163-181.

Peck, Jamie y Tickell, Adam (2007). Conceptualizing neoliberalism, thinking Thatcherism, en Helga Leitner, Jamie Peck y Eric Sheppard (eds.) Contesting neoliberalism. Urban frontiers. New York, United States: The Guilford Press. p. 26-50.

Plan Estratégico Territorial Formosa (2015). El plan que conduce a la visión de largo plazo, Provincia de Formosa. Argentina. 255p.

PEDL (Planes Estratégicos de Desarrollo Local). (2013). Informe Final General Enrique Mosconi Formosa Fase VII. Argentina: Consejo Federal de Inversiones, Fundación Arandú. 126p.

Porter, Michael (1998). Clusters and the New Economics of Competition. En: Harvard Business Review. Massachusetts, United States: Harvard College, p. 77-90.

Redacción Rio Negro (2013). Eurnekian se quedó con la petrolera CGC. El grupo pagó u\$ss 200 millones por el 81 \%. https://www.rionegro.com.ar/eurnekian-se-quedo-con-la-petrolera-CgC-JQRN_1075832/

Reynals, Olaguer. (2003). Producción de petróleo provincias Argentinas. Regalías petroleras provincia de Formosa. Formosa, Argentina: CFI-Concejo Federal de Inversiones. 85p.

Reynals, Olaguer (2005a). Control de regalías provincia de Formosa. Formosa, Argentina: CFI-Consejo Federal de Inversiones. Informe Final, 68p. 
Reynals, Olaguer. (2005b). Reserva de petróleo en las cuencas argentinas y control de regalías provincia de Formosa. Formosa, Argentina: CFI-Consejo Federal de Inversiones. 68p.

RIABM (2010). Anuario 2010, bosque modelo de Iberoamérica. RIABM, 151p.

Rofman, Alejandro y Romero, Luís. (1997). Sistema Socioeconómico y Estructura Regional en la Argentina. Buenos Aires: Amorrortu, 328p.

Schorr, Martín, Ferrreira, Esteban y Gorenstein, Silvia (2012). Complejos Productivos con encadenamientos industriales en el norte argentino: algodón, azúcar y foresto-industria, En: Silvia Gorenstein (org.) ¿Crecimiento o Desarrollo? El ciclo reciente en el norte argentino. Silvia Gorenstein/organizadora. Buenos Aires, Argentina: Miño y Dávila, 207p.

Seoane, José., Tadei, Emilio y Clara Algranati (2013). Extractivismo, despojo y crisis climática. Desafíos para los movimientos sociales y los proyectos emancipatorios de América Latina. Buenos Aires, Argentina: Herramienta, El Colectivo y GEAL, 336p.

Sued, Gabriel (2006). Los secretos de Gildo Insfrán, el modelo de gobernante perpetuó. En: La Nación. Buenos Aires. Argentina.

Vaca, Josefina y Cao, Horacio (2004). La división regional del trabajo en la Argentina: nuevos elementos y tradicionales desequilibrios. En: Realidad Económica, № 202 p. 65-86. 